\title{
In-situ Scanning Transmission X-Ray Microscopy of Catalytic Solids and Related Nanomaterials
}

\author{
Frank M. F. de Groot, ${ }^{*}$ Emiel de Smit, Matti M. van Schooneveld, Luis R. Aramburo, and \\ Bert M. Weckhuysen ${ }^{*[a]}$
}

\begin{abstract}
The present status of in-situ scanning transmission X-ray microscopy (STXM) is reviewed, with an emphasis on the abilities of the STXM technique in comparison with electron microscopy. The experimental aspects and interpretation of X-ray absorption spectroscopy (XAS) are briefly introduced and the experimental boundary conditions that determine the potential applications for in-situ XAS and in-situ STXM studies are dis-
\end{abstract}

cussed. Nanoscale chemical imaging of catalysts under working conditions is outlined using cobalt and iron FischerTropsch catalysts as showcases. In the discussion, we critically compare STXM-XAS and STEM-EELS (scanning transmission electron microscopy-electron energy loss spectroscopy) measurements and indicate some future directions of in-situ nanoscale imaging of catalytic solids and related nanomaterials.

\section{Introduction}

Over the last years, a number of instrumental developments in microscopy have improved the ability to image nanomaterials with a spatial resolution in the nanometer range. These microscopes (or nanoscopes) provide the atomic positions, elemental determination and chemical information such as the valence, spin state and bonding properties. If these nanoscopic techniques are performed under in-situ conditions, one can even obtain new information on the nanometer scale of an active system. This allows for the study of many, fundamentally interesting processes such as catalytic reactions, minerals weathering, colloidal synthesis and hydrogen storage materials. When considering catalytic solids the main, entangled, goals of the in-situ nanoscopic experiments can be briefly stated as:

1. Providing nanoscopic information for the rational design of new catalyst materials.

2. Adding to the fundamental understanding of the behavior of nanomaterials under working conditions and in a range of different environments.

3. Providing novel tools to look at materials in new ways.

We explicitly limit this review article to real space probes that give a direct view on materials with a resolution of $20 \mathrm{~nm}$ or better. Thereby, we omit the important range of experiments that determine the local structure via X-ray diffraction or electron diffraction. We also omit all techniques that have an intrinsic spatial resolution, governed by the diffraction limit of light, above $100 \mathrm{~nm}$. Note that the diffraction limited $(0.5 \lambda)$ resolution $(R)$ of electromagnetic radiation can be given as $R$ $(\mathrm{nm}){ }^{*} E(\mathrm{eV}) \cong 620$. Visible light with an energy of $1 \mathrm{eV}$ has a diffraction limited resolution of $620 \mathrm{~nm}$ and VUV light with an energy of $10 \mathrm{eV}$ has $R=62 \mathrm{~nm}$. All probes using IR, Raman, UV/ $V$ is and fluorescence microscopic techniques are not further discussed in this paper and we refer to other recent papers. ${ }^{[1,2]}$
The remaining nanoscopic techniques can be divided into three main groups: (1) Scanning probe and near field microscopes, (2) Electron microscopes and (3) X-ray microscopes. Scanning probe microscopes determine objects with (sub)nanometer dimensions from close distance. This near field approach reaches essentially the spatial resolution as determined by the probe. Scanning probe techniques include scanning tunneling microscopy (STM), atomic force microscopy (AFM) and scanning near field optical microscopy (SNOM). These techniques are immensely important to determine the geometric and electronic structure of surfaces. The information content is, as a rule, limited to (near) surface information and because of the near field probe, the probed surface must be relatively flat. Non-exposed internal surfaces are not accessible with scanning probe techniques. Catalytic activity very often takes place within micro and/or mesoporous structures implying that not only the external surface of a catalyst is of importance. Examples include the active sites within zeolites and enzymes. The catalytic active sites in these systems cannot be studied with probes that only map the outside of the system. Transmission electron microscopy (TEM) and transmission X-ray microscopy (TXM) sample a column of material through the system of study. As such they provide information on both the surface structure and the internal structure of a material.

In the remainder of this article, we will not further discuss scanning probe techniques and focus on the comparison be-

\footnotetext{
[a] Prof. Dr. F. M. F. de Groot, E. de Smit, M. M. van Schooneveld,

L. R. Aramburo, Prof. Dr. B. M. Weckhuysen

Inorganic Chemistry and Catalysis

Debye Institute for Nanomaterials Science

Utrecht University

Sorbonnelaan 16, 3584 CA Utrecht (Netherlands)

Fax: $(+31) 302511027$

E-mail:f.m.f.degroot@uu.nl

b.m.weckhuysen@uu.nl
} 
tween TXM and TEM. We first briefly introduce the basics of soft X-ray absorption spectroscopy. The spectral interpretation and experimental limitations and detection routes are discussed. Scanning TXM (SXTM) microscopes are introduced, including a brief comparison with alternative $X$-ray and electron microscopy techniques. The in-situ measurements are discussed for the case of bulk experiments, using the various detection modes. Using the combined knowledge of XAS spectral shapes, STXM microscopes and in-situ detection, their combination into in-situ STXM experiments is discussed. A number of examples are given of the measurements that have been published. A separate section focuses more on the nanoreactor design that is crucial for the in-situ STXM experiments. We end with some future perspectives of this promising technique for the characterization of a wide range of nanomaterials, including but not limited to heterogeneous catalysis.

\section{Soft XAS}

The present range of STXM microscopes mainly covers the energy range between 200 and $2400 \mathrm{eV}$. We limit our discussion to this soft $\mathrm{X}$-ray energy range.

\subsection{Soft X-Ray Core Levels and Elemental Mapping}

The energy range from $200 \mathrm{eV}$ to $2000 \mathrm{eV}$ covers the $1 \mathrm{~s}$ core states or $\mathrm{K}$ edges of the elements from carbon $(280 \mathrm{eV})$ to phosphorus $(2150 \mathrm{eV})$, as indicated in Figure 1. We have selected five STXM beamlines at the following synchrotrons: NSLS Brookhaven; ${ }^{[3]}$ BESSY Berlin;; $;{ }^{[4]}$ SLS Villingen (Pollux) $;{ }^{[5]}$ CLS Saskatoon; ${ }^{[6]}$ ALS Berkeley. ${ }^{[7,8]}$ An updated list of STXM beamlines is provided at the XASEELS website. ${ }^{[9]}$

Figure 1 includes the important elements $\mathrm{C}, \mathrm{N}, \mathrm{O}$ and also $\mathrm{Mg}, \mathrm{Al}, \mathrm{Si}$ and $\mathrm{P}$. The $2 \mathrm{~s}$ core states are not studied with regard to their spectral shape due to their large spectral broadening. The soft $X$-ray $2 p$ core states ( $L_{2,3}$ edges) range from potassium $(290 \mathrm{eV})$ to $\mathrm{Sr}(2000 \mathrm{eV})$. Note that the potassium $\mathrm{L}_{2,3}$ edge is close in energy to the carbon $\mathrm{K}$ edge, implying that both spectral shapes overlap. One should always be aware of potential

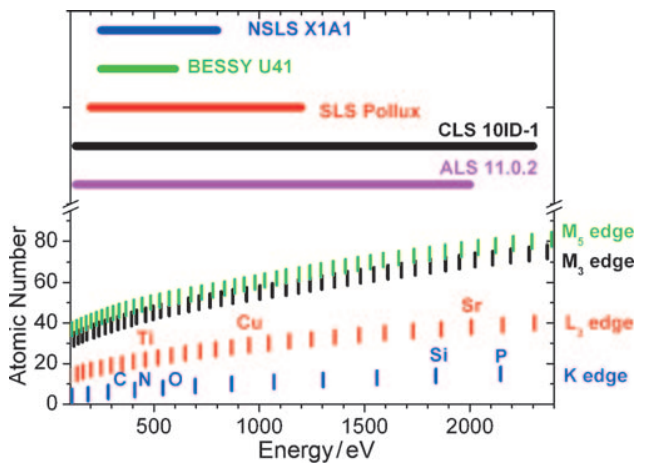

Figure 1. Bottom: The binding energies of the $K$ (blue), $L_{3}$ (red), $M_{3}$ (black) and $M_{5}$ (green) edges in the soft X-ray range between 100 and $2400 \mathrm{eV}$. The indicated elements are shown in the same colour as the edge to which they belong. Top: The X-ray range of five STXM microscopes, respectively NSLS X1A1, BESSY U41, SLS Pollux, CLS 10ID-1 and ALS 11.0.2. overlap of spectral shapes of different elements, also due to second order $\mathrm{X}$-ray energies that are sometimes inevitable. In particular the $3 \mathrm{~d}$ transition metal ions $\mathrm{Ti}, \mathrm{V}, \mathrm{Cr}, \mathrm{Mn}, \mathrm{Fe}, \mathrm{Co}, \mathrm{Ni}$ and $\mathrm{Cu}$ are important for catalysis (and many other fields) and are often studied, also because they provide very rich $L_{2,3}$ edge spectral shapes. The soft $X$-ray $3 p$ core states $\left(M_{2,3}\right.$ edges) range from $\mathrm{Sr}(270 \mathrm{eV})$ to $\mathrm{Gd}(1688 \mathrm{eV})$ and the soft $\mathrm{X}$-ray $3 \mathrm{~d}$ core states $\left(M_{4,5}\right.$ edge) range from $\mathrm{Ru}(280 \mathrm{eV})$ to $\mathrm{Yb}(1576 \mathrm{eV})$. The $M_{4,5}$ edges include all rare earth ions that provide very rich spectral shapes and also very high absorption cross sections. For the $5 \mathrm{~d}$ elements, in principle the $\mathrm{N}_{2,3}$ edges are positioned in the soft X-ray range, but these edges are too broad to be useful for chemical speciation. However, using the specific absorption of any core level one can obtain quantitative elemental maps in a STXM microscope of all elements with a core level in the soft $\mathrm{X}$-ray range. This can be done for example by so-called jump ratio imaging, in which the ratio between a recorded map just before and just after the edge are calculated. As can be inferred from Figure 1, this includes essentially all elements starting from carbon, which underlines the wide potential for application of the STXM methodology in different fields of research.

\subsection{The Interpretation of Soft XAS Spectra and Chemical Contrast}

Soft X-ray $\mathrm{K}$ edges can be well interpreted as mapping the empty states of the element under study. The dipole selection rule implies that the element specific empty p-projected density of states is observed. This facilitates the comparison with electronic structure calculations for the molecular or solid sample studied. The variation in the empty states implies variation in the XAS spectral shape, which can be used for chemical contrast. The spectral shapes of carbon, nitrogen and oxygen containing systems reveal a large variation in spectral shapes and, as such, are ideal for chemical contrast. ${ }^{[10]}$

The transition metal $L$ edges and the rare earth $M$ edges cannot be interpreted with a density of states concept, as their spectral shape is dominated by so-called multiplet effects induced by the core hole in the final state. ${ }^{[11]}$

As an example Figure 2 shows the variation in spectral shape as a function of valence in the case of manganese oxides. ${ }^{[12]}$ One observes a rich spectral fine structure allowing detailed chemical analysis. Transition metal $L$ edges are dominated by the large overlap between the core $2 p$ wave function and the valence band $3 d$ states. Because this interaction spreads the states over some $10 \mathrm{eV}$, it is known as the multiplet effect. In addition, the $2 p$ spin-orbit coupling splits the $L$ edge into its $L_{3}$ and $L_{2}$ components. Next to these atomic effects, the crystal field effects and the effects of charge fluctuations (charge transfer) dominate the spectral shape analysis. ${ }^{[13]}$ Crystal field multiplet analysis yields accurate information on the metal valence, spin state, the site symmetry and the crystal field strength. ${ }^{[14,15]}$ Covalent systems can be analyzed with charge transfer effects and yield information on the angular dependence in the hybridization and the importance of $\pi$ bonding. ${ }^{[16,17]}$ A number of detailed $L$ edge spectra and charge 


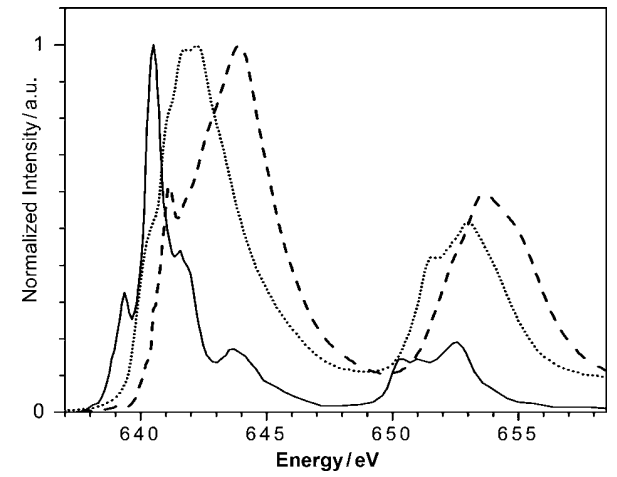

Figure 2. The $2 p$ XAS spectra of three manganese oxides. $\mathrm{Mn}^{[2+]} \mathrm{O}$ (solid), $\mathrm{Mn}^{[3+]}{ }_{2} \mathrm{O}_{3}$ (dotted) and $\mathrm{Mn}^{[4+]} \mathrm{O}_{2}$ (dashed).

transfer multiplet analysis has been applied to catalytic systems, for example Fischer-Tropsch catalysts, ${ }^{[12]}$ Fe/ZSM-5 systems ${ }^{[18]}$ and Mn/ZSM-5 systems. ${ }^{[19]}$

\subsection{Detection Modes and Experimental Boundary Conditions}

Soft X-rays have a strong interaction with matter. This implies that transmission experiments are only possible for solid samples of limited thickness. In addition, the transmission through gas atmospheres is also affected by significant soft X-ray absorption, limiting the $\mathrm{X}$-ray path through the gas phase to several 100 microns. The STXM nanoreactors, which will be discussed in Section 5 of this review article, have two $20 \mathrm{~nm}$ SiNx windows and a gas interaction length of about $50 \mu \mathrm{m}$ which have over $80 \%$ transmission over the whole soft $\mathrm{X}$-ray range. It can be observed in Figure 3 that 50 micron of air and $\mathrm{CO}$ gas have some absorption at the oxygen, nitrogen and carbon edges. This affects in particular the study of edges below $800 \mathrm{eV}$. Gas absorption starts to play a significant role for $>1 \mathrm{~mm}$ path lengths. It can be concluded that with the given nanoreactor parameters, both the gas phase and the windows do not significantly affect the measurements. Of course, if $\mathrm{CO}$ gas is used, the carbon and oxygen $\mathrm{K}$ edges are dominated by the gas phase spectrum.
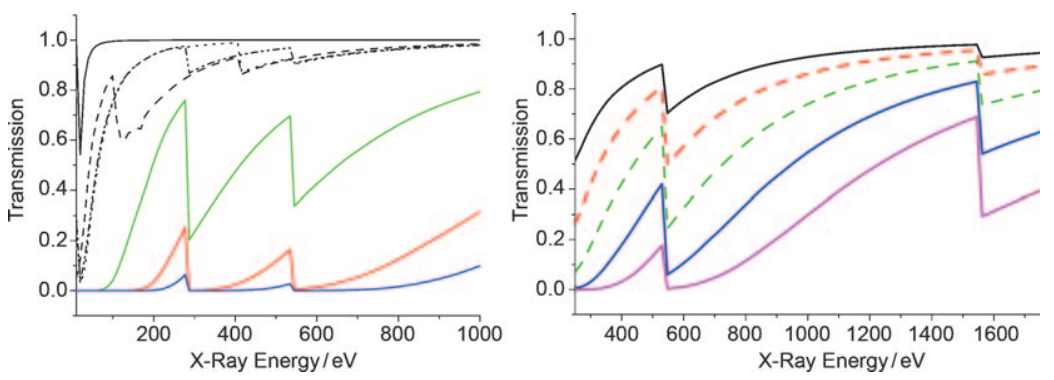

Figure 3. Left: The soft X-ray transmission through 50 micron of 1 bar $\mathrm{H}_{2}$ (black), $20 \mathrm{~nm} \mathrm{SiNx}$ (dashed), 50 micron air (dotted), 50 micron CO (dash-dotted), $1 \mathrm{~mm} \mathrm{CO} \mathrm{(green),} 5 \mathrm{~mm} \mathrm{CO}$ (red), $1 \mathrm{~cm} \mathrm{CO}$ (blue), and $1 \mathrm{~cm} \mathrm{O}_{2}$ (blue); Right: The transmission through, from top to bottom, $100 \mathrm{~nm}, 200 \mathrm{~nm}, 400 \mathrm{~nm}, 800 \mathrm{~nm}$ and $1.6 \mathrm{micron} \mathrm{Al}_{2} \mathrm{O}_{3}$. $\mathrm{All}$ curves are calculated from the Center for X-Ray Optics website software, as can be found at www-cxro.lbl.gov.
The sample thickness for soft X-rays must ideally be in the (sub)micron range, dependent also on concentration and elemental composition. Figure 3 (right) shows the effect of increasing thickness, where we note that the curves only show the atomic background; the edge spectral features can be twice as intense. It can be seen that for $\mathrm{Al}_{2} \mathrm{O}_{3}$, the oxygen $\mathrm{K}$ edge remains measurable between $100 \mathrm{~nm}$ and 1.6 micron, though at this largest thickness, the transmission at the edge is essentially zero, also implying a non-linear signal. The Al K edge has largest contrast at the thickness of 1.6 micron. Note that the choices of the edges that are studied significantly affect the ideal sample thickness. For less concentrated samples, it is important that enough edge contrast is visible, which implies thicker samples, even at the expense of little overall transmission, as has been shown for the non-linear response of the iron $L_{3}$ edge. ${ }^{[20]}$

Because of these $\mathrm{X}$-ray transmission induced sample limitations, traditionally soft XAS spectra have been measured with electron yield detection or fluorescence yield detection. Yield methods use the core hole decay, which gives rise to electrons and X-rays escaping from the surface of the substrate. Detection of these decay products, allows the measurement of samples with arbitrary thickness. The main issue is to establish if the measured yield channel is indeed proportional to the X-ray absorption cross section. For soft X-rays Auger decay dominates over fluorescence decay. Over $90 \%$ of the core holes decay via Auger channels. With the total electron yield (TEY) method, one detects all electrons that emerge from the sample surface, independent of their energy. The interaction of electrons with solids is much larger than the interaction of $\mathrm{X}$ rays, which implies that the electrons that escape from the sample originate close to the surface and the probing depth of TEY is approximately 2 to $5 \mathrm{~nm}$. In other words, electron yield turns XAS into a surface technique. In principle, a STXM microscope allows TEY measurements.

The fluorescent decay of the core hole can also be used as the basis for the XAS measurement. The photon created in the fluorescent decay has a mean free path of the same order as the incoming $X$-ray, which implies that there will be saturation effects if the sample is not dilute (the ideal sample thickness is $1 / e$ of the absorption depth). It can be shown that for dilute materials the background absorption dominates the absorption of the specific edge, and the measured intensity is proportional to the absorption coefficient. The main effect for concentrated (over 5 at. \%) samples is saturation, implying a nonlinear response and the reduction of the peak heights and depths and as such a blurring of the spectrum. A number of additional complications exist for fluorescence yield. For example fluorescence channels have an energy dependence over an absorption edge, implying poten- 
tial distortions in fluorescence yield spectra with respect to the XAS spectral shape. ${ }^{[21]}$

\section{X-Ray and Electron Microscopes}

\subsection{STXM Microscopy}

The first STXM instrument, was designed by Kirz and Rarback (1985). ${ }^{[22]}$ In 1992, Ade et al. measured XAS spectra of organic species with a spatial resolution of $60 \mathrm{~nm}$ using the STXM at NSLS. ${ }^{[11]}$ They used the carbon $\mathrm{K}$ edge contrast to determine the amount and chemical nature of carbon species, for example they distinguished polypropylene, polyacrylonitrile, and polystyrene in blended samples. Over the last fifteen years, STXM has been applied to a range of systems, with an emphasis on polymer science, ${ }^{[3,23,24]}$ biology and the study of the organic phase in catalytic reactions, for example the study of diesel soot. ${ }^{[25]}$ As we will show below, STXM is ideally suited to study, in addition to the organic phase (by their carbon and oxygen edges) also the inorganic phase via their metal edges, as is discussed in detail in Section 4.

In a STXM microscope, a synchrotron soft X-ray absorption beamline is used to illuminate a Fresnel zone plate, as is schematically indicated in Figure 4. The zone plate characteristics

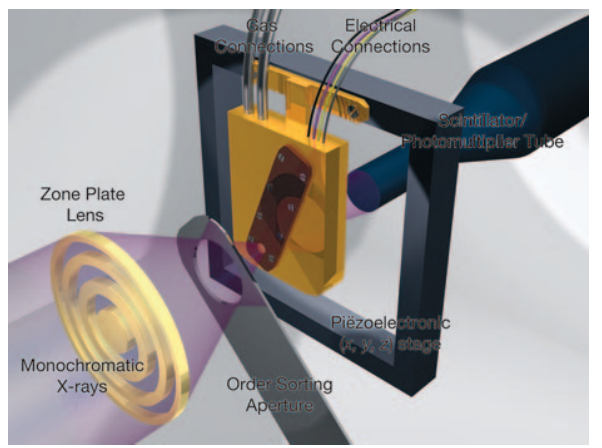

Figure 4. Lay out of a STXM microscope, with from left to right, the zone plate lens, the order sorting aperture, the nanoreactor and the scintillator $\mathrm{X}$ ray detector.

determine the spot size to which the X-ray beam is focused. Present day STXM beamlines have spot sizes ranging from 10 to $40 \mathrm{~nm} \cdot{ }^{[26]}$ The focal length is dependent on spot size and Xray energy and is in the order of a few millimeters. An important consequence of these short focal lengths is the short working distance between the sample position and the zone plate, which present a severe design limitation for in-situ reactor cells. The position of an aperture between the zone plate and sample further shortens the allowed reactor working distance. The sample is placed at the focus of the zone plate and scanned while detecting the transmitted X-rays. The energy resolution of a STXM microscope is typically $0.1 \mathrm{eV}$ at the carbon $\mathrm{K}$ edge $(280 \mathrm{eV})$ and $0.3 \mathrm{eV}$ at the copper $\mathrm{L}$ edge $(900 \mathrm{eV})$, which is adequate for soft X-ray absorption edges as their lifetime broadening is of the same order of magnitude. Present STXM microscopes ${ }^{[27]}$ have mechanical scanning and interferometer based control systems which provide sample scan-ranges from the $\mu \mathrm{m}$ to the $\mathrm{cm}$ range, with a minimum step size of $\sim 5 \mathrm{~nm}$, and measurement speeds of typically $1 \mathrm{~ms}$ per pixel. ${ }^{[28]}$ Hitchcock et al. provide an overview of the STXM microscopes that exist at various synchrotron radiation sources. ${ }^{[29]}$

\subsection{Scanning PhotoEmission Microscopy (SPEM)}

The single zone-plate STXM design can be used to measure the XAS spectrum in transmission mode, fluorescence yield or electron yield detection. In case of very dilute systems, say below the 1000 ppm range, FY is the most appropriate detection method, as the transmission contrast will be very small. Also electron yield detection can be combined with a scanning $X$-ray microscope, turning the technique into a surface science tool. Instead of measuring the total electron yield, one can also use an electron analyzer to measure the XPS spectrum using a zone-plate focused X-ray. ${ }^{[30]}$ This technique is known as scanning photoemission microscopy (SPEM), which provides $\mathrm{nm}$ range resolution chemical speciation of surfaces. A wide range of catalysis-oriented surface science studies have been performed using SPEM. ${ }^{[31,32]}$ Because electrons are detected the measurements are as a rule performed in vacuum or at lowpressure.

\subsection{Full Field X-Ray Microscopes: TXM and CCTXM}

Full-field transmission X-ray microscopy (TXM) uses two zone plates, allowing the synchronous detection of an image plane, implying faster data acquisition. The disadvantages are significant lower energy resolution $(1.0 \mathrm{eV}$ at $500 \mathrm{eV})$ and a higher radiation dose per signal. The reduced energy resolution strongly limits the options for chemical speciation, implying that full field TXM is mainly applicable to element selective mapping. However, a recent design has decoupled the monochromator from the zone plates allowing high energy-resolution TXM measurements. ${ }^{[33]}$ A newly developed design is the so-called chemical contrast TXM (CCTXM) with a moderate 1 micron spatial resolution. It uses a parallel beam of a XAS beamline that is measured after transmission through the sample with an X-ray CCD with high spatial resolution. ${ }^{[34]}$ An important advantage with respect to X-ray microscopes that make use of zone plates, is that there are no space limitations with respect to the sample environment, which facilitates in-situ experimental chambers. CCTXM therefore offers many options for the study of catalytic systems under in-situ conditions.

\subsection{Electron Microscopes: STEM-EELS, TEM-EELS and X-PEEM}

Scanning transmission electron microscopy (STEM) combined with electron energy loss spectroscopy (EELS), is the electron analogue of STXM-XAS. The spatial resolution of electron microscopy is in general much higher than for X-ray microscopy. With a typical resolution of $0.2 \mathrm{~nm}$ instead of $20 \mathrm{~nm}$ its resolving power is a factor of 100 higher. Experiments under mbar 
conditions are performed in so-called environmental TEM microscopes. However, as yet, no STEM-EELS experiments have been reported under 1 bar pressure conditions. In the discussion we will compare the advantages and disadvantages of STEM-EELS and STXM-XAS in some detail.

TEM-EELS experiments, making use of a full field electron microscope instead of a scanning microscope, are more likely to make the study of catalytic systems under relevant conditions possible. Recently a TEM experiment has been performed under 1 bar conditions on a catalytic sample. ${ }^{[35]}$ Also temperatures up to $500^{\circ} \mathrm{C}$ have been reached during in-situ TEM-EELS measurements. ${ }^{[36]}$ In-situ sample treatments like ion bombardments have also been reported for TEM-EELS experiments. ${ }^{[37]}$ For a recent detailed comparison between TEM and TXM we refer to a review as provided by Hitchcock et al. ${ }^{[38]}$

A combined $\mathrm{X}$-ray and electron microscope design is the socalled X-ray photoemission electron microscopes (PEEM) ${ }^{[39-41]}$ which uses a full field X-ray beam and the detection of the electrons emitted from the sample surface. Because X-PEEM uses electron detection, experiments under gas atmosphere are not possible. In addition, X-PEEM implies using a high-voltage electrostatic lens detector system in close proximity to the sample, which complicates the measurements of mixed metalinsulator systems such as metal nanoparticles on oxide supports.

\subsection{A Comparison of Resolutions and Sample Thicknesses}

In this section, we compare the important boundary conditions for STEM-EELS and STXM-XAS spectromicroscopic measurements, which are i) the spatial resolution and ii) the maximal sample thickness.

Figure 5 gives an indication of the range of accessible experimental resolutions and sample thicknesses. The curve for STEM-EELS assumes a $100 \mathrm{keV}$ electron beam. The resolution of electron microscopes in EELS mode, is between 0.1 and $0.5 \mathrm{~nm}$, with some possible improvements to less than $0.1 \mathrm{~nm}^{[42-44]}$ This is only an indication for the range of values,

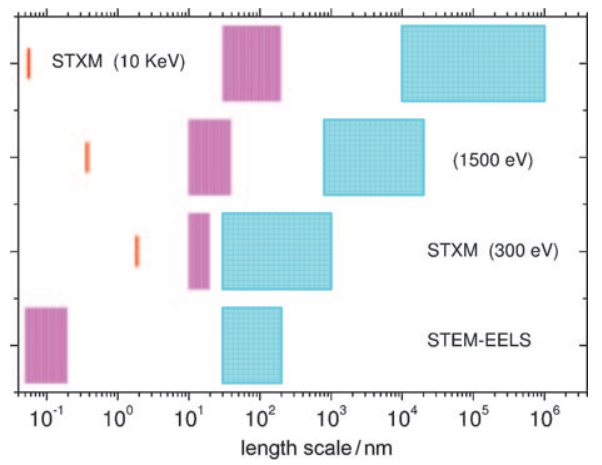

Figure 5. The range of experimental, spatial resolutions (pink) and maximal sample thicknesses (blue) are indicated on a logarithmic scale for, from bottom to top, STEM-EELS, STXM at $300 \mathrm{eV}$, STXM at $1.5 \mathrm{keV}$ and STXM at $10 \mathrm{keV}$. The range of sample thicknesses is limited as a consequence of the $\mathrm{X}$-ray attenuation but also by spectral deformations due to saturation effects. The red vertical lines indicate the diffraction limited resolution of the $\mathrm{X}$-rays, given as $R(\mathrm{~nm}){ }^{*} E(\mathrm{eV}) \cong 620$. as the resolution of STEM-EELS also depends on the primary energy and a range of details in electron source, optics, monochromators and electron analyzers. Chemical contrast in EELS is not generated by photon absorption processes as in XAS, but through inelastic scattering of electrons. The amount of energy being lost in such a scattering event is characteristic for the element (and chemical environment) with which the incoming electrons scattered. The electron mean free path is mainly dependent of the applied electron voltage of the source and is dominated by the inelastic scattering of electrons in solids. ${ }^{[45]}$ However, the maximal sample thickness for chemical contrast imaging is dependent on the material. In case of EELS edges with a large scattering cross-section (a high EELS probability), for example the rare earth $M_{4,5}$ edges, the maximal sample thickness for reliable quantitative information based on spectral shapes is limited to less than $30 \mathrm{~nm}$.

STXM experiments have, at present, an optimal resolution of approximately $10 \mathrm{~nm} \cdot{ }^{[33,46]}$ As discussed above, the diffraction limited resolution $(R)$ of electromagnetic radiation is $R(\mathrm{~nm}) * E$ $(\mathrm{eV}) \cong 620$. X-rays at $100 \mathrm{eV}$ have a diffraction limit of $6.2 \mathrm{~nm}$ and at $1000 \mathrm{eV}$ of $0.62 \mathrm{~nm}$. The maximal sample thickness of STXM is strongly dependent on energy as discussed in Section 2.3. In particular if one uses an X-ray energy exactly at a strong absorption edge in the soft $\mathrm{X}$-ray range, for example the $\mathrm{Ca} L$ edge at $350 \mathrm{eV}$, the sample thickness for which the signal is not distorted can be as low as $50 \mathrm{~nm}$. This does not mean that thicker samples can not be measured, but the strong absorption modifies the spectral shape and apparent optical density due to non-linear absorption. ${ }^{[20]}$ Systems with dilute amounts of carbon or calcium can be up to 1 micron thick.

STXM experiments at $1500 \mathrm{eV}$ have a significantly longer probing depth, implying measurements up to $\sim 20$ micron, again dependent on the nature of the sample and the presence of X-ray absorption edges. For example, Al metal will have saturation effects in its spectral shape with a thickness of less than 20 micron, but systems with lower amounts of aluminum such as Al-doped zeolites can be easily measured. If the same zone plate is used as for the $300 \mathrm{eV}$ measurements, the same spectral resolutions could be obtained, but the higher energy implies a lower diffraction efficiency at the zone plate lens and therefore lower $\mathrm{X}$-ray intensity.

For hard X-rays, for example at $10 \mathrm{keV}$, the soft X-ray zone plates yield too low scattering cross sections and one needs different, thicker, zone plates. In practice, the hard X-ray spatial resolution is at present still above $100 \mathrm{~nm}$ for most beamlines, though improvements can be expected in the next years. ${ }^{[4]}$ The much reduced $X$-ray absorption strength and scattering of hard $\mathrm{X}$-rays increases the possible sample thickness towards the $\mathrm{mm}$ range. Hard $X$-ray microscopy experiments in the micron range are very interesting for catalysis as the hard $X$ rays allow realistic catalytic conditions and the detection of the $5 \mathrm{~d}$ elements, for example Pt. Beautiful space and time resolved hard X-ray experiments have been performed by Grunwaldt et al. ${ }^{[48]}$ Alternative micron range hard $\mathrm{X}$-ray experiments involve the so-called TEDDI technique. ${ }^{[49,50]}$ 


\section{In-Situ Soft XAS of Catalytic Solids and Related Materials}

In-situ soft XAS measurements of various nanomaterials have been performed in transmission, electron yield and fluorescence yield modes. Recently, Forsberg et al. measured steel corrosion on an $1 \times 1 \mathrm{~mm}$ sized iron film of $50 \mathrm{~nm}$ thick, using their newly developed CCTXM microscope with a pixel resolution of a few microns. ${ }^{[34]}$ Such transmission soft XAS experiments need thin samples. Apart from this limitation, there is a large freedom for the design of in-situ reactors.

Knop-Gericke and co-workers have developed a number of in-situ soft XAS reaction chambers based on conversion electron yield (CEY) detection. ${ }^{[32,51]}$ In CEY, the emitted electron ionizes the gas that is present above the sample. The degree of ionization is measured by two collector plates that detect respectively i) the pure gas phase signal and ii) the gas phase and surface signal. By subtraction, the surface component can be derived. In case of metal spectra, no gas phase signal is present and the surface spectrum can be directly obtained. The maximum pressure range obtainable with CEY is in the mbar range. This technique is ideal to study the surface spectrum of a catalyst sample, which can be measured during reactions.

Heijboer et al. used the CEY-XAS measurements to study the oxidation and reduction behavior of iron complexes inside zeolite systems. ${ }^{[1,52]}$ Figure 6 shows Fe/ZSM- 5 under 2 mbar $\mathrm{O}_{2}$ and under 2 mbar $\mathrm{He}$ at $350^{\circ} \mathrm{C}$. The $\mathrm{O}_{2}$ spectrum can be identified as a pure $\mathrm{Fe}^{3+}$ spectrum and the He spectrum relates to pure $\mathrm{Fe}^{2+}$. Using these references, the atmosphere is switched from $\mathrm{O}_{2}$ to $\mathrm{He}$ at $25^{\circ} \mathrm{C}$. One observes a partial reduction from 2.9 to 2.6 in a matter of minutes, revealing the sensitivity of the iron complexes to the gas atmosphere, even at room temperature. CEY-XAS is a very sensitive technique and is able to measure low concentrations of dopants in catalysts, as has been nicely shown for the case of the $L_{2,3}$ edge of $5 \mathrm{wt} \% \mathrm{Cu}$ in an iron Fischer-Tropsch catalyst. ${ }^{[53]}$

Fischer and co-workers have developed in-situ soft XAS based on fluorescence yield detection. ${ }^{[54]}$ Fluorescence detection is a photon-in photon-out technique and as such is not hampered by strong electron scattering. In addition, thick samples can be measured. A disadvantage is the low fluorescence yield for soft X-ray edges. Sambisavan et al. showed the FY de-
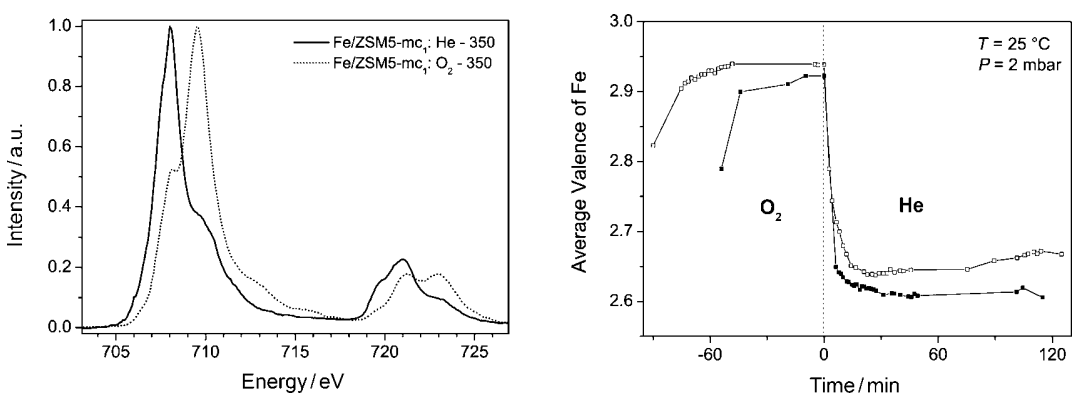

Figure 6. Left: The in-situ detected CEY iron 2p XAS spectrum of Fe/ZSM5 under oxygen and He atmosphere. Right: The switch from 2 mbar $\mathrm{O} 2$ to $\mathrm{He}$ at $25 \mathrm{C}$ tected carbon $\mathrm{K}$ edge XAS for the in-situ determination of changes in the adsorbed state of propylene in the Ag-exchanged zeolite $Y$ materials. ${ }^{[55]}$ Combing bulk sensitive $(100 \mathrm{~nm}) \mathrm{FY}$ with surface sensitive $(5 \mathrm{~nm}) \mathrm{EY}$, they observed differences between bulk and surface reactivity. A transformation was observed from the physisorbed state of propylene in the pores to a chemisorbed state on the surface of zeolite $Y$ at temperatures above $125 \mathrm{~K}$.

\section{In-Situ STXM of Catalytic Solids}

In-situ STXM experiments combine the in-situ conditions of a XAS experiment with a STXM microscope. In addition to the reactor limitations with respect to the $\mathrm{X}$-ray path through the sample $(<1 \mu \mathrm{m})$ and gas phase $(<500 \mu \mathrm{m})$, there is the additional complication of the short microscope optical path length, limiting the distance between the sample and the zone plate aperture to a few millimeters, depending on the zone plate resolution and excitation energy.

The first in-situ STXM experiments were performed by Drake et al. ${ }^{[56]}$ They designed a cell based on a glass wafer. The metal resistive heater and microchannels for the gas flow were integrated onto the glass wafer, resulting in an X-ray path length of 800 micron and maximum pressure/temperature conditions of $1 \mathrm{bar} / 300^{\circ} \mathrm{C}$. Using this reactor cell, they studied the reduction and oxidation of a silica-supported $\mathrm{Cu}$ catalyst, by measuring the $\mathrm{Cu} \mathrm{L}_{3}$ XAS spectrum. Using the contrast between $\mathrm{Cu}^{1+}$ and $\mathrm{Cu}^{2+}$ oxides, oxidation state specific images of the catalyst were measured. It was found that $\mathrm{Cu}^{2+}$ disappears during the exposure of the oxidized sample to $4 \% \mathrm{CO}$ in He while increasing the temperature from 25 to $200^{\circ} \mathrm{C}$.

The same in-situ reactor cell has been used by Swart et al. to measure the distribution of manganese and cobalt in $\mathrm{Mn}$ doped $\mathrm{Co} / \mathrm{TiO}_{2}$ catalysts. ${ }^{[57]}$ Figure 7 shows the elemental maps of $\mathrm{Mn}$ and Co for a 1 micron sized composite particle. The $2 p$ XAS spectra of $\mathrm{Mn}$ and $\mathrm{Co}$ indicate the presence of $\mathrm{CO}_{3} \mathrm{O}_{4}$ and mixed $3+/ 4+$ manganese oxide. The in-situ $2 p$ XAS spectra were measured at room temperature in air at 1 bar. The elemental Mn and Co STXM images show an uneven distribution of the elements over the particle. At the top of the particles a $\mathrm{Mn}$ rich phase is observed, while at the bottom more Co is detected. The attempts to measure this system under 1 bar of a flowing gas at elevated temperatures were not successful, due to sample drift, interference with the zone plate characteristics and reactor failures.

\subsection{In-Situ STXM Under Work- ing Conditions}

The two experiments discussed above are in-situ STXM experiments, however they were not measured on a catalyst system that was active. The first in-situ STXM-XAS experiments on a working catalyst have been pub- 

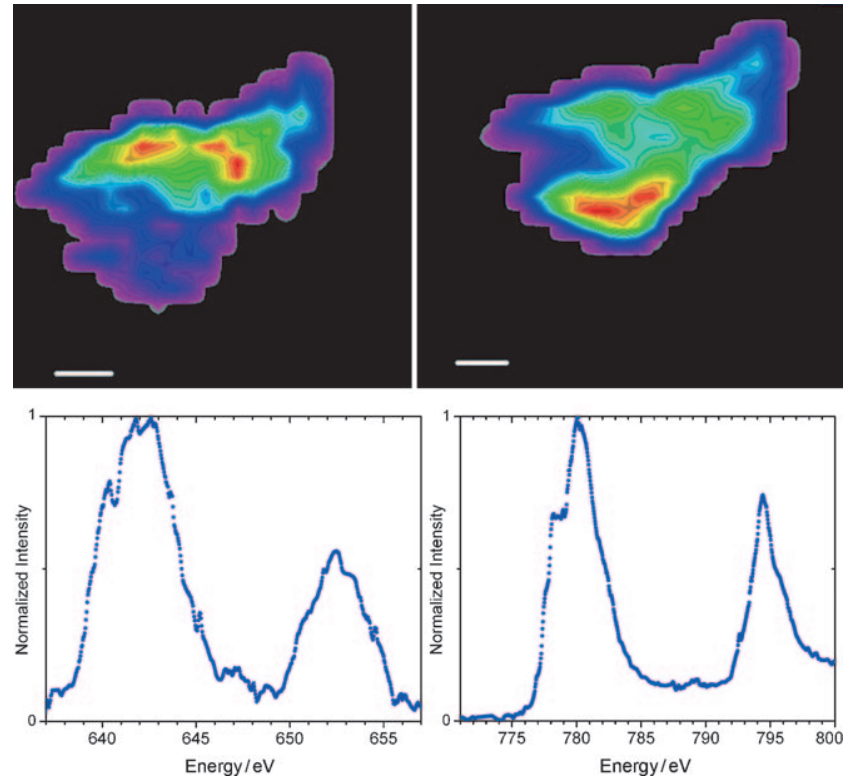

Figure 7. Top: Contour images of $\mathrm{Mn}$ (left) and Co (right) of a Mn-doped Co/ $\mathrm{TiO}_{2}$ catalyst sample. The scale bars indicate $200 \mathrm{~nm}$. Bottom: The $\mathrm{Mn} 2 \mathrm{p}$ XAS spectrum (left) and the Co $2 p$ XAS spectrum (right).

lished in 2008 by de Smit et al. ${ }^{[58]}$ They measured $\mathrm{Fe}_{2} \mathrm{O}_{3} / \mathrm{CuO} /$ $\mathrm{K}_{2} \mathrm{O} / \mathrm{SiO}_{2}$, an iron-based Fischer-Tropsch Synthesis (FTS) catalyst under working conditions. The Fischer-Tropsch reaction enables the production of high-purity chemicals and transportation fuels from sources other than conventional crude oil, most notably natural gas, coal and biomass.

The in-situ STXM experiment first tracked the reduction of supported iron oxide particles upon heating to $350^{\circ} \mathrm{C}$ in $\mathrm{H}_{2}$ (1 bar) and, subsequently, the working catalyst during the FTS reaction at $250^{\circ} \mathrm{C}$ in synthesis gas (1 bar). The carbon $1 \mathrm{~s}$ XAS $(284 \mathrm{eV})$, oxygen $1 \mathrm{~s}$ XAS $(543 \mathrm{eV})$ and iron $2 \mathrm{p}$ XAS $(707 \mathrm{eV})$ were measured each $35 \times 35 \mathrm{~nm}^{2}$ pixel. The Fe $2 p$ XAS was used to map the iron valence and the oxygen $\mathrm{K}$ edge to distinguish between different oxygen-containing species $\left(\mathrm{SiO}_{2}\right.$ and iron oxides; cf. Figure 8). The carbon $\mathrm{K}$ edge was measured to image the type and location of carbon species present in the catalyst during reaction.

The extent and rate of reduction of the iron oxide phase were shown to depend on its chemical surroundings and the extent of interaction with the underlying support material. Up

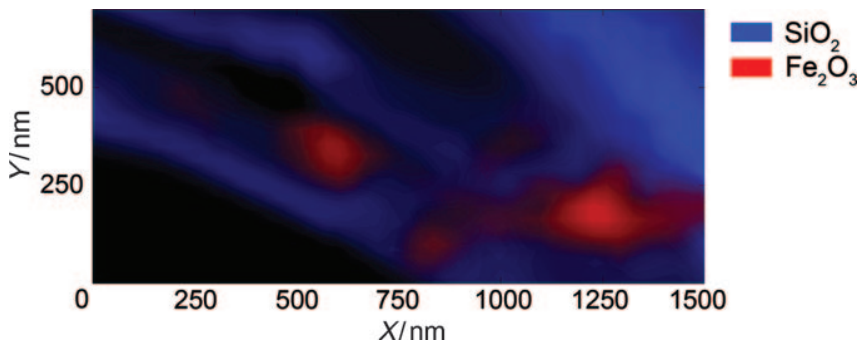

Figure 8. Elemental map of $\mathrm{SiO}_{2}$ (blue) and $\mathrm{Fe}_{2} \mathrm{O}_{3}$ (red) of an iron-based Fischer-Tropsch catalyst, using the oxygen $\mathrm{K}$ edge and iron L edge STXM XAS spectra. to $400^{\circ} \mathrm{C}$ very inhomogeneous reduction occurs with metallic regions co-existing with oxide regions. Above $400^{\circ} \mathrm{C}$, the distribution of Fe over the particle becomes more and more homogeneous with increasing temperature and no regions are observed where $\mathrm{Fe}$ metal is the main contributing species. ${ }^{[59]}$ These results illustrate the complexity of the interpretation of bulk reduction experiments and their extrapolation to nanoscale phenomena. The correlations of the carbon $\mathrm{K}$ edge of the substrate with the iron L edge of the catalyst after FTS conditions, indicated that carbon is mainly formed at the iron nanoparticles, whereby the nature of carbon is different at sites away from the iron nanoparticles. For further details, we refer to the original publications. ${ }^{[58,59]}$ As such, this nanoscale chemical imaging technique provides insights into the local particle morphology and chemical reduction behavior of a complex Fischer-Tropsch catalyst system.

We have also performed in-situ STXM on magnetite $\mathrm{Fe}_{3} \mathrm{O}_{4}$ nanoparticles. Figure 9 shows the $\mathrm{Fe}_{3} \mathrm{O}_{4}$ nanoparticles under 1 bar of hydrogen at $150^{\circ} \mathrm{C}$. The average iron $L$ edge spectrum at $150^{\circ} \mathrm{C}$ is essentially a pure magnetite spectrum, which indicates that the whole sample consists of the magnetite $\mathrm{Fe}_{3} \mathrm{O}_{4}$ phase. At $350^{\circ} \mathrm{C}$, the iron $\mathrm{L}$ edge has changed and now appears as a combination of iron oxide and iron metal. The iron L edge is measured each $35 \times 35 \mathrm{~nm}^{2}$ pixel and the spectral shape of each pixel is simulated as a linear combination of $\mathrm{Fe}_{3} \mathrm{O}_{4}$, a divalent iron oxide and iron metal. Figure 9 shows the reduction at $350^{\circ} \mathrm{C}$, where the sample is reduced in a very inhomogeneous manner with regions that remain essentially $\mathrm{Fe}_{3} \mathrm{O}_{4}$ (blue) next to regions that are largely reduced to iron metal (red). At higher temperatures the sample completely reduces to iron metal. An important finding is that the reduction
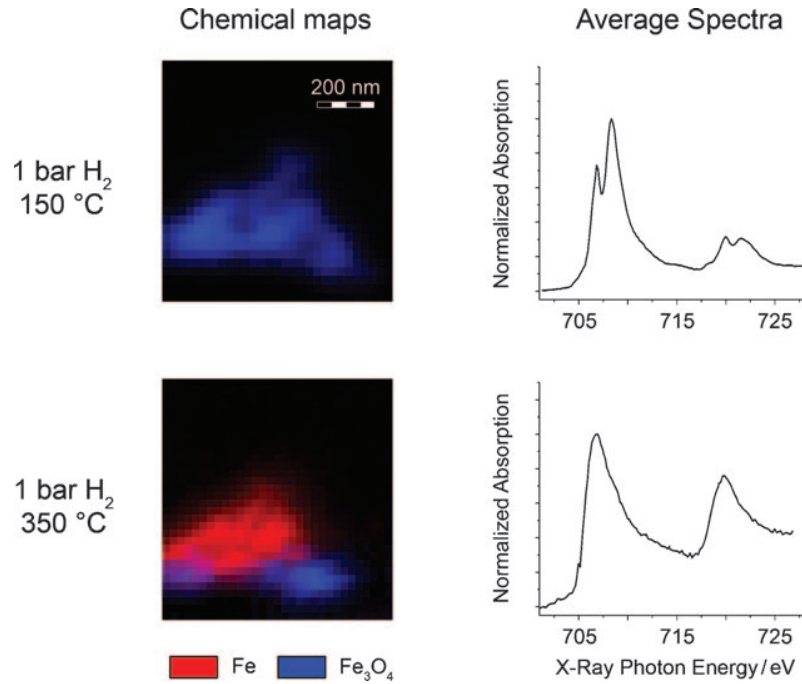

Figure 9. Chemical maps (left) of the iron-oxide particle and $\mathrm{Fe} \mathrm{L}_{2,3}$-edge spectra averaged over the entire particle (right) for reduction in $\mathrm{H}_{2}$ at $150^{\circ} \mathrm{C}$ (top) and $350^{\circ} \mathrm{C}$ (bottom). Blue pixels indicate the presence of $\mathrm{Fe}_{3} \mathrm{O}_{4}$; red pixels indicate the presence of $\mathrm{Fe}^{0}$. The pixel dimensions of the chemical map are $35 \times 35 \mathrm{~nm}^{2}$. The valence contours maps indicate the distribution of the average valence of iron species over the particle. The iron phase is significantly reduced to $\mathrm{Fe}^{0}$ at $350^{\circ} \mathrm{C}$. 
of iron oxides is quite inhomogeneous, with metal co-existing with oxide regions on a scale of $50 \mathrm{~nm}$.

Related to this, we have measured reduction-oxidation cycles of an iron oxide particle. Figure 10 shows that during the initial reduction, the particle largely retained its original
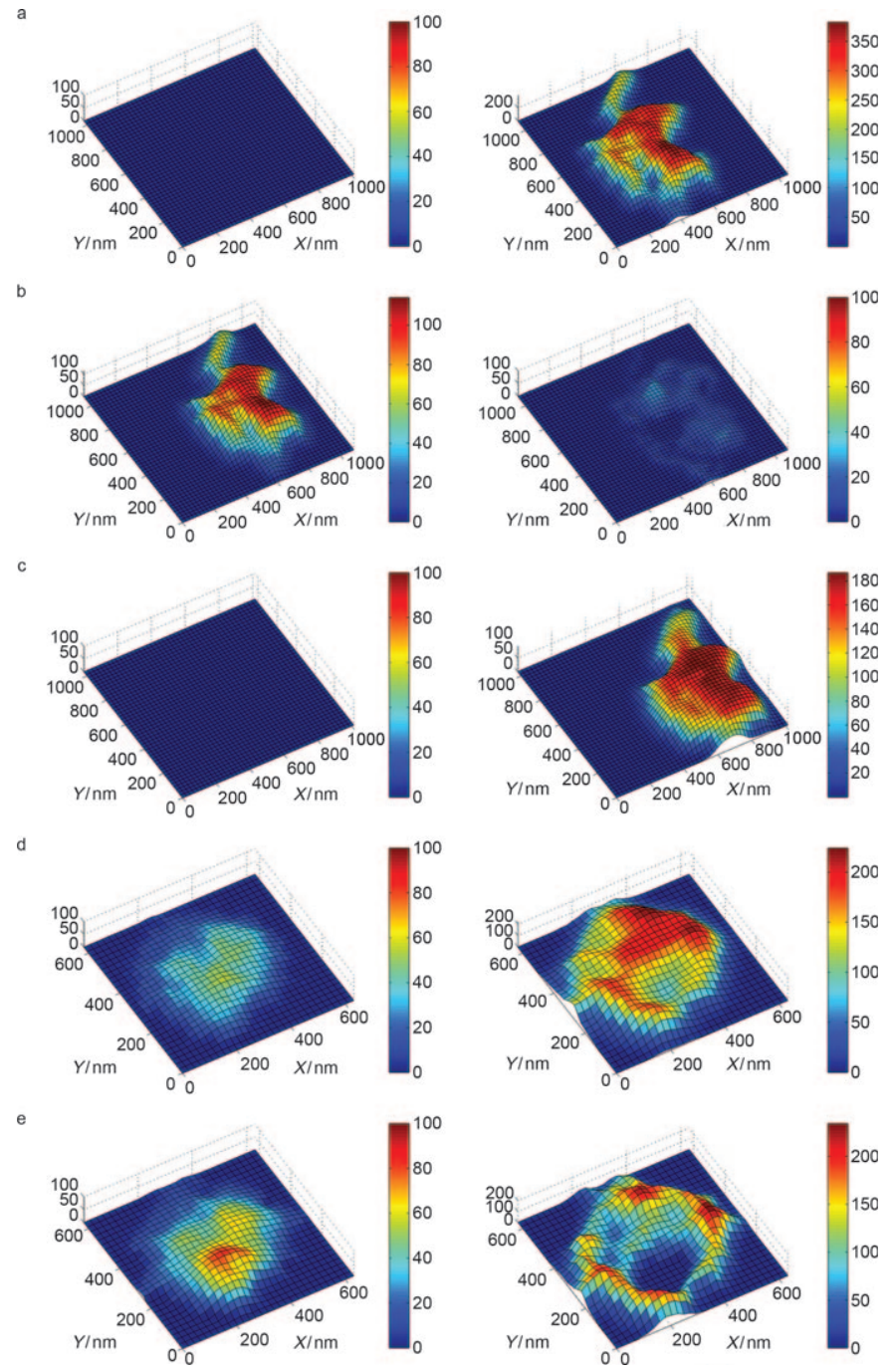

Figure 10. Thickness plots (in $\mathrm{nm}$ ) of Fe metal (left) and $\mathrm{Fe}_{2} \mathrm{O}_{3} / \mathrm{Fe}_{3} \mathrm{O}_{4}$ (right) of an iron oxide particle under a reduction-oxidation-reduction cycle. a) Before the cycle, b) reduction at $350^{\circ} \mathrm{C}$, c) after re-oxidation at $350^{\circ} \mathrm{C}$, and after the second reduction treatment at d) $400^{\circ} \mathrm{C}$ and e) $450^{\circ} \mathrm{C}$.

shape and shows a similar inhomogeneous composition as indicated in Figure 9. The calculated thicknesses show that the particle is significantly thinner after the treatment, in line with the expected decrease in volume upon reduction of $\mathrm{Fe}_{2} \mathrm{O}_{3}$ to $\mathrm{Fe}$. Re-oxidation yields pure $\mathrm{Fe}_{3} \mathrm{O}_{4}$, where the shape is slightly smoother and more uniform (but lower) in thickness than the initial shape. During the second reduction cycle, the particle only starts reducing at higher temperatures $\left(-400^{\circ} \mathrm{C}\right)$. Upon reduction, the particle shape changes dramatically, transforming into a more spread-out spherical particle. This is likely due to the mobility of the iron phase at higher temperatures (i.e. sintering). However, the particle could not be fully reduced under the same conditions and at $450^{\circ} \mathrm{C}$, the particle still consisted largely of $\mathrm{Fe}_{3} \mathrm{O}_{4}$. This behavior is rationalized by the slow sintering of the individual smaller clusters of $\mathrm{Fe}_{2} \mathrm{O}_{3}$ at the start of the reduction treatment into larger metallic Fe particles upon the first reduction. Upon subsequent oxidation, the growth of the oxide structure causes further erosion of the initial shape of the particle. As the reduction is limited by the diffusion of oxygen atoms to the surface, the second reduction is significantly more difficult due to the dense nature of the particle, now consisting of a $\mathrm{Fe}_{3} \mathrm{O}_{4}$ structure. Upon the formation of metallic $\mathrm{Fe}$ at $400^{\circ} \mathrm{C}$, the shape of the particle changes again.

\subsection{Nanoreactors}

There are several possible designs for in-situ STXM nanoreactors reported in literature. One common goal in the design of nanoreactors is the minimization of the path length that X-rays have to travel through the gas and/or liquid reactant phase. This will minimize X-ray attenuation and yield higher signal intensities. The earliest design for catalytic studies were based on glass wafer manufacturing technology ${ }^{[56]}$ and involved several steps in masking, etching gas channels in the glass substrate, and depositing the Al based resistive heater. The metal resistive heater and microchannels for the gas flow were integrated onto the glass wafer, and the cell was sealed using $200 \mathrm{~nm} \mathrm{Si} \mathrm{N}_{4}$ windows. This cell design resulted in a total X-ray path length of $800 \mu \mathrm{m}$ and maximum pressure/temperature conditions of $1 \mathrm{bar} / 260^{\circ} \mathrm{C}$. However, depending on the gas phase reactants, diluted gas mixtures had to be used in order to minimize gas phase attenuation.

Another recent cell design is specifically designed for measuring in-situ STXM in electrochemical (solution) experiments and involves an electrolyte reservoir wafered between two $\mathrm{Si}_{3} \mathrm{~N}_{4}$ windows. ${ }^{[60]}$ The cell is equipped with an anode or cathode that can in principle be manufactured of any conductor. In their experiment the group followed the electrodeposition of $\mathrm{Ni}$ on an $\mathrm{Au}$ film. The total path length of the cell is about $500 \mathrm{~nm}$, sufficiently short to have enough transmission of $X$ rays over the 200-2000 eV soft X-ray range. However, unfortunately the cell is not equipped with a heater which limits it application for catalytic experiments.

The design of the current in-situ STXM nanoreactors is based on (micro electro mechanical systems) MEMS technology. The nanoreactors were initially designed for in-situ TEM studies $^{[35]}$ and have a reduced total gas phase path length of $\sim 50 \mu \mathrm{m}$. Furthermore, the concentrated spiral heater design $(200 \times 200 \mu \mathrm{m})$ ensures isothermal heating over a significant area. The $1.2 \mu \mathrm{m}$ thick $\mathrm{Si}_{3} \mathrm{~N}_{4}$ membranes, with small $\sim 5 \times 5 \mu \mathrm{m}^{2}$ windows were the thickness is etched down to $10 \mathrm{~nm}$, ensures robustness of the window material while ensuring minimum $X$ ray attenuation. The current design of the cell allows for experiments up to $\sim 2 \mathrm{bar}$ and $500^{\circ} \mathrm{C}$. Furthermore, the cell adapter and nanoreactor were developed to have a minimal thickness. This is necessary in order to allow a minimum distance between the order sorting aperture, which filters out higher order diffractions of the zone plate lens, and the sample plane. The current minimum working distance ob- 
tained by this cell is $\sim 800 \mu \mathrm{m}$. It is noted here that we recently demonstrated that at the lower energy edges ( $C, N, O$ Kedges), the $2 \times 1.2 \mu \mathrm{m} \mathrm{Si}_{3} \mathrm{~N}_{4}$ membranes are almost opaque to $X$-ray light and as a result, the $10 \mathrm{~nm}$ thick $5 \times 5 \mu \mathrm{m}$ windows can in principal be used as apertures. As a result, the order sorting aperture is not required for these measurements and the restricted working distance between the nanoreactor and STXM components is somewhat improved. Further optimization of the cell design also allows liquid phase experiments, where, depending on the used liquid and the absorption edges of interest the total path length has to be below $\sim 10 \mu \mathrm{m}$ to ensure the transmission of enough X-ray photons. The nanoreactors are supported on an adaptor which is mounted on an interferometrically controlled, piezoelectric stage that can translate the sample in the X-ray beam with nanometer precision. The adapter is designed to hold two separate nanoreactors and connects the reactors to the external gas supply and electronics (cf. Figure 11).
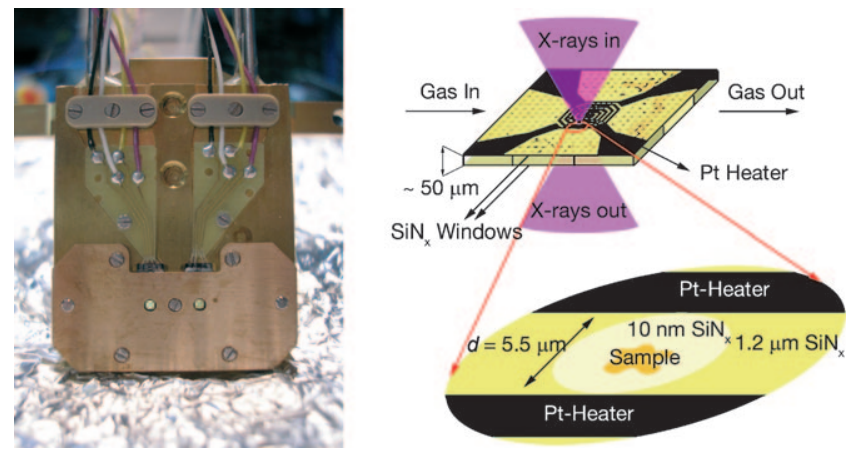

Figure 11. Left: The nanoreactor adapter as used in the in-situ STXM experiments showing the electrical and gas connectors for the two nanoreactors at the top. The X-ray windows are gold colored and are positioned left and right of the center screw. Right: Artistic impression of the nanoreactor windows indicating the spiral heater and the $\sim 5 \times 5 \mu \mathrm{m}^{2}$ windows used to investigate the material of interest.

\section{Comparison of STXM-XAS with STEM-EELS}

X-ray and electron microscopy techniques have been recently compared by Hitchcock et al. ${ }^{[38]}$ and also by Thomas et al. ${ }^{[61]}$ We refer to these papers for alternative views on this issue. The main difference between STXM-XAS and STEM-EELS is the significantly stronger interaction with matter of electrons compared with X-rays. Table 1 gives a brief overview and in the subsequent paragraphs we briefly discuss these aspects, including energy resolution, energy range, time resolution, spatial resolution, detection modes, detection limits, sample thickness, sample conditions, sample damage and tomography options.

\section{Energy Resolution}

The energy resolution of soft X-rays on a STXM beamline is typically between $E / \Delta E=2500$ and $E / \Delta E=7500$, implying $0.04-$ $0.12 \mathrm{eV}$ resolution at the carbon $\mathrm{K}$ edge. De facto this implies that for solids the experimental resolution is mainly deter-
Table 1. Overview of the comparisons between STXM-XAS and STEMEELS.

\begin{tabular}{|lll|} 
& STXM-XAS & STEM-EELS \\
\hline Spatial resolution & $10-30 \mathrm{~nm}$ & $0.1-0.5 \mathrm{~nm}$ \\
Energy resolution & $0.04-0.12 \mathrm{at} 300 \mathrm{eV}$ & $0.2-0.5 \mathrm{eV}$ \\
& $0.2-0.6 \mathrm{at} 1500 \mathrm{eV}$ & \\
& $E / \Delta E=2500-7500$ & \\
Energy range & $200-2000 \mathrm{eV}$ & $2-2000 \mathrm{eV}$ \\
Data collection & Single energy & All energies \\
Time resolution & $1 \mathrm{~ms} /$ pixel & $10 \mathrm{~ms} /$ pixel \\
& $100 \mathrm{~ms} /$ pixel/edge & \\
Detection modes & Transmission (T) & Transmission (T) \\
& Fluorescence Yield (FY) & \\
Sample thickness & Electron Yield (EY) & \\
Element sensitivity & $50 \mathrm{~nm}-20$ micron & $<500 \mathrm{~nm}$ \\
& $1000 \mathrm{ppm}(\mathrm{T})$ & $1000 \mathrm{ppm}(\mathrm{T})$ \\
In-situ pressure & $10 \mathrm{ppm}(\mathrm{FY})$ & vacuum \\
& $1 \mathrm{bar}$ & $(1 \mathrm{bar}$ in TEM) \\
Beam damage & High & Very high \\
\hline
\end{tabular}

mined by the lifetime broadening of the core holes, which is in the range of $0.2-0.3 \mathrm{eV}$ for soft $\mathrm{X}$-ray $\mathrm{K}$ and $\mathrm{L}$ edges. With regard to STEM-EELS, the energy resolution varies significantly from microscope to microscope. Most EELS-dedicated microscopes have a core level energy resolution of $0.2-0.5 \mathrm{eV}$, that is, of the order of the lifetime broadening.

\section{Spatial Resolution}

The spatial resolution is 0.1 and $0.5 \mathrm{~nm}$ for regular STEM-EELS microscopes, ${ }^{[44,62,63]}$ which is a factor 100 better than the spatial resolution in STXM-XAS. ${ }^{[46]}$ An important experimental future development will be the combination of ex-situ TEM and in-situ STXM-XAS measurements using the same nanoreactor and looking at the same parts of the material.

\section{Detection Modes}

An important advantage of STEM-EELS is that all core levels are measured simultaneously. In this case the energy resolution is limited by the detection channels of the detector, but this allows for sufficient energy resolution to probe elements and their valences in a spatially resolved mode. For an improved spectral resolution, one can measure a specific edge, thereby increasing the number of detector channels per energy interval. In STXM-XAS, the X-ray energy is set to one particular value and only at that energy the $X$-ray absorption is measured. One can make use of this property by limiting the detection of a few relevant energies over an element edge. If one knows exactly at what energies a characteristic signal is present, one can make low dose STXM-XAS measurements on radiation sensitive samples. In addition, STXM-XAS can be measured with EY and turn into a surface probe, or it can be measured with $\mathrm{FY}$ and turn into a technique for ultra dilute species. The measurement of STXM with an XPS detector yields the as scanning photoemission microscopy (SPEM) technique as discussed in Section 3.2. ${ }^{[31,32]}$ 


\section{Time Resolution}

The time for the measurement of a single pixel can be roughly set at $1 \mathrm{~ms}$ for STXM and $10 \mathrm{~ms}$ for STEM-EELS, ${ }^{[28]}$ where this value can vary depending on required data quality, sample composition and sample thickness. In STEM-EELS, the whole spectrum is measured at once implying that a 100 point spectrum effectively needs $10 \mathrm{~ms} /$ pixel for STEM-EELS and $100 \mathrm{~ms} /$ pixel for STXM, ignoring additional dead time. A $64 \times 64$ pixel image then takes $\sim 7$ min for STXM, again ignoring dead time. We did not discuss dedicated time-resolved EELS experiments that reach femtosecond time resolution ${ }^{[64]}$ or the picosecond time resolution that is reached with time-resolved TXM measurements. ${ }^{[65]}$

\section{Detection Limits}

STEM-EELS and STXM-XAS are transmission experiments and the required contrast for a core level signal implies that spectral shapes of dilute species can not be measured. The concentration required to measure reliable and quantitative spectra is strongly dependent on sample composition. As a rule, one can state that concentrations above 5 atomic \% (5000 ppm) are required for good spectra and above $1 \%$ (1000 ppm) for elemental maps. If STXM-XAS is measured with FY, these detection limits go down to $\mathrm{a} \sim 10 \mathrm{ppm}$ for high $\mathrm{Z}$ elements.

\section{Sample Thickness}

STEM-EELS requires a sample less than $100-500 \mathrm{~nm}$ thin. STXM-XAS can handle samples with thicknesses up to 20 micron at $1.5 \mathrm{keV}$ and in the millimeter range for hard $X$ rays. This implies that materials with an intrinsic thickness above 1 micron, can not be studied by STEM-EELS. In addition, for many materials it is difficult or impossible to prepare proper slices/lamellae for electron microscopy measurements. The much thicker specimen that can be handled with STXMXAS offers a wider and more flexible range of materials that can be studied, including objects such as intact biological cells.

\section{In-Situ Sample Conditions}

As of yet, TEM has been applied at 1 bar and $500^{\circ} \mathrm{C}^{[35]}$ in non carbonaceous gases, though 1 bar measurements have not yet been reported for STEM-EELS. STXM-XAS can be measured up to $2 \mathrm{bar}$ and up to $550^{\circ} \mathrm{C}$ in the presence of carbonaceous gases. These numbers for pressure and temperature are expected to increase when the dedicated high-pressure and high-temperature nanoreactors, that are being designed, will become available. Hard X-ray experiments can be performed under extreme conditions, including high-pressure diamond anvil cells.

\section{Sample Damage}

EELS scattering cross-sections are relatively weak as compared to X-ray absorption cross-sections. Therefore STEM-EELS re- quires a high radiation dose in comparison with normal TEM or STXM-XAS. This implies that the sample damage is potentially high, including knock on damage, carbon deposition, sputtering and electrostatic charging. In STXM-XAS a highly focused X-ray beam is used, which especially at resonance, generates large amount of electrons, yielding damage from electrostatic charging and carbon deposition. Combining all beam damage effects and the required doses for imaging, as a rule it is found that STXM-XAS causes less damage than STEMEELS ${ }^{[66]}$ For example, the $10 \mathrm{~nm}$ nanoreactor SiNx windows are not noticeably affected in a STXM, whereas a STEM-EELS measurement tends to destroy them. For details on sample damage due to electron and $\mathrm{X}$-ray beams we refer to dedicated papers, ${ }^{[62,67-69]}$ for example the special issue that focuses on beam damage in J. Elec. Spec. ${ }^{[70]}$

\section{Tomography}

Conceptually, STXM tomography is analogous to STEM tomography. This also implies that for $X$-rays, it is more convenient to perform tomography with a parallel beam with a TXM microscope. Tomography drastically increases the exposure time, hence the potential damage. STXM has the advantage of higher detection efficiency than TXM, implying that in principle STXM tomography needs less X-ray dose per area of studied material.

In conclusion, it can be stated that STEM-EELS offers better spatial resolution and the simultaneous detection of all core levels. STXM-XAS can handle large samples and a wider range of sample conditions including catalysis under working conditions. In addition it has favorable tomography conditions and can be turned into a surface probe or into a probe for ultra dilute impurities maintaining its $\sim 20 \mathrm{~nm}$ spatial resolution.

\section{Future Developments}

We are of the opinion that there is a bright future for submicron chemical imaging using in-situ STXM techniques. All materials that contain elemental or chemical contrast on the $20 \mathrm{~nm}$ length scale can be studied under reaction conditions. This applies to heterogeneous catalysis, and to fuel cells, batteries, hydrogen storage materials and other material studies that focus on the elemental and chemical gradients. One of major the advantages of STXM is that both the organic as the inorganic part of the nanomaterials can be investigated.

Future developments will very likely improve the temperature and pressure range of nanoreactors up to $1000^{\circ} \mathrm{C}$ and $10 \mathrm{bar}$, thereby extending the range of feasible materials science and catalysis experiments. An important future development is the performance of in-situ STXM tomographic experiments. STXM of ultra dilute samples with concentrations down to $100 \mathrm{ppm}$ are not straightforward in transmission mode, implying that fluorescence yield detection must be used. Such fluorescence yield based experiments would allow the mapping of impurities/promoters in heterogeneous catalyst and in materials science in general. 
STXM will probably never reach the $0.1 \mathrm{~nm}$ spatial resolution as obtained by electron microscopy. STEM-EELS experiments on the other hand will be unfeasible for many samples and for many sample conditions. ${ }^{[8]} A$ useful solution would be to combine in-situ STXM-XAS experiments with ex-situ STEM-EELS experiments on the same sample positions. One could imagine measuring a catalyst ex-situ with STEM-EELS, performing some treatment in-situ with a STXM nanoreactor and performing a second STEM-EELS experiment after reaction, at all times probing the same sample region.

\section{Acknowledgements}

We acknowledge financial support for some of the work described in this review article from the Netherlands National Science Foundation (NWO/VICl program) as well as the Netherlands Research School Combination Catalysis (NRSC-C) and Shell Global Solutions.

Keywords: electron microscopy - Fischer-Tropsch catalysts in-situ scanning transmission X-ray microscopy (STXM) nanomaterials

[1] B. M. Weckhuysen, Angew. Chem. 2009, 121, 5008-5043; Angew. Chem Int. Ed. 2009, 48, 4910-4943.

[2] M. B. J. Roeffaers, B. F. Sels, H. Uji-i, F. C. De Schryver, P. A. Jacobs, D. E. De Vos, J. Hofkens, Nature 2006, 439, 572-575.

[3] H. Ade, A. P. Smith, H. Zhang, G. R. Zhuang, J. Kirz, E. Rightor, A. Hitchcock, J. Electron Spectrosc. Relat. Phenom. 1997, 84, 53-71.

[4] U. Wiesemann, J. Thieme, P. Guttmann, R. Früke, S. Rehbein, B. Niemann, D. Rudolph, G. Schmahl, J. Phys. IV 2003, 104, 95.

[5] J. Raabe, G. Tzvetkov, U. Flechsig, M. Boge, A. Jaggi, B. Sarafimov, M. G. C. Vernooij, T. Huthwelker, H. Ade, D. Kilcoyne, T. Tyliszczak, R. H. Fink, C. Quitmann, Rev. Sci. Instrum. 2008, 79, 10.

[6] K. V. Kaznatcheev, C. Karunakaran, U. D. Lanke, S. G. Urquhart, M. Obst, A. P. Hitchcock, Nucl. Instrum. Methods Phys. Res. Sect. A 2007, 582, $96-$ 99.

[7] T. Warwick, H. Ade, S. Cerasari, J. Denlinger, K. Franck, A. Garcia, S. Hayakawa, A. Hitchcock, J. Kikuma, S. Klingler, J. Kortright, G. Morisson, M Moronne, E. Rightor, E. Rotenberg, S. Seal, H. J. Shin, W. F. Steele, B. P. Tonner, J. Synchrotron Radiat. 1998, 5, 1090-1092.

[8] T. Warwick, H. Ade, D. Kilcoyne, M. Kritscher, T. Tylisczcak, S. Fakra, A. Hitchcock, P. Hitchcock, H. Padmore, J. Synchrotron Radiat. 2002, 9 254-257.

[9] F. de Groot XASEELS website, www.anorg.chem.uu.nl/people/staff/ FrankdeGroot/xaseels.htm. 2010, 3.

[10] J. G. Chen, Surf. Sci. Rep. 1997, 30, 1-152.

[11] H. Ade, X. Zhang, S. Cameron, C. Costello, J. Kirz, S. Williams, Science 1992, 258, 972-975

[12] F. Morales, F. M. F. de Groot, P. Glatzel, E. Kleimenov, H. Blühm, M. Havecker, A. Knop-Gericke, B. M. Weckhuysen, J. Phys. Chem. B 2004, 108 $16201-16207$.

[13] F. de Groot, A. Kotani, Core Level Spectroscopy of Solids, Taylor and Francis, New York, 2008, p. 3.

[14] S. P. Cramer, F. M. F. de Groot, Y. Ma, C. T. Chen, F. Sette, C. A. Kipke, D. M. Eichhorn, M. K. Chan, W. H. Armstrong, E. Libby, G. Christou, S Brooker, V. McKee, O. C. Mullins, J. C. Fuggle, J. Am. Chem. Soc. 1991 113, 7937-7940.

[15] F. de Groot, Coord. Chem. Rev. 2005, 249, 31-63.

[16] R. K. Hocking, E. C. Wasinger, F. M. F. de Groot, K. O. Hodgson, B. Hedman, E. I. Solomon, J. Am. Chem. Soc. 2006, 128, $10442-10451$.

[17] E. C. Wasinger, F. M. F. de Groot, B. Hedman, K. O. Hodgson, E. I. Solomon, J. Am. Chem. Soc. 2003, 125, 12894-12906.
[18] W. M. Heijboer, A. A. Battiston, A. Knop-Gericke, M. Havecker, R. Mayer H. Bluhm, R. Schlogl, B. M. Weckhuysen, D. C. Koningsberger, F. M. F. de Groot, J. Phys. Chem. B 2003, 107, 13069-13075.

[19] D. Radu, P. Glatzel, A. Gloter, O. Stephan, B. M. Weckhuysen, F. M. F. de Groot, J. Phys. Chem. C 2008, 112, 12409-12416.

[20] S. Hanhan, A. M. Smith, M. Obst, A. P. Hitchcock, J. Electron Spectrosc. Relat. Phenom. 2009, 173, 44-49.

[21] F. M. F. de Groot, M. A. Arrio, P. Sainctavit, C. Cartier, C. T. Chen, Solid State Commun. 1994, 92, $991-995$.

[22] J. Kirz, H. Rarback, Rev. Sci. Instrum. 1985, 56, 1.

[23] I. N. Koprinarov, A. P. Hitchcock, C. T. McCrory, R. F. Childs, J. Phys. Chem B 2002, 106, 5358-5364.

[24] D. Slep, J. Asselta, M. H. Rafailovich, J. Sokolov, D. A. Winesett, A. P. Smith, H. Ade, Y. Strzhemechny, S. A. Schwarz, B. B. Sauer, Langmuir 1998, 14, 4860-4864.

[25] A. Braun, F. E. Huggins, N. Shah, Y. Chen, S. Wirick, S. B. Mun, C. Jacobsen, G. P. Huffman, Carbon 2005, 43, 117-124.

[26] W. L. Chao, B. D. Harteneck, J. A. Liddle, E. H. Anderson, D. T. Attwood, Nature 2005, 435, 1210-1213.

[27] A. L. D. Kilcoyne, T. Tyliszczak, W. F. Steele, S. Fakra, P. Hitchcock, K. Franck, E. Anderson, B. Harteneck, E. G. Rightor, G. E. Mitchell, A. P. Hitchcock, L. Yang, T. Warwick, H. Ade, J. Synchrotron Radiat. 2003, 10, $125-136$.

[28] M. Howells, C. Jacobsen, T. Warwick, Principles and Applications of Zone Plate X-Ray Microscopes in The Science of Microscopy, Kluwer Press, Dordrecht, 2007.

[29] A. P. Hitchcock, J. J. Dynes, J. R. Lawrence, M. Obst, G. D. W. Swerhone, D. R. Korber, G. G. Leppard, Geobiology 2009, 7, 432-453.

[30] H. J. Shin, M. K. Lee, Nucl. Instrum. Methods Phys. Res. Sect. A 2001, 467, 909-912.

[31] A. Barinov, P. Dudin, L. Gregoratti, A. Locatelli, T. O. Mentes, M. A. Nino, M. Kiskinova, Nucl. Instrum. Methods Phys. Res. Sect. A 2009, 601, 195202.

[32] A. Knop-Gericke, E. Kleimenov, M. Havecker, R. Blume, D. Teschner, S. Zafeiratos, R. Schlogl, V. I. Bukhtiyarov, V. V. Kaichev, I. P. Prosvirin, A. I. Nizovskii, H. Bluhm, A. Barinov, P. Dudin, M. Kiskinova, Adv. Catal. 2009, $52,213$.

[33] S. Rehbein, S. Heim, P. Guttmann, S. Werner, G. Schneider, Phys. Rev. Lett. 2009, 103, 4.

[34] J. Forsberg, C. J. Englund, L. C. Duda, Ultramicroscopy 2009, 109, 1157 1163.

[35] J. F. Creemer, S. Helveg, G. H. Hoveling, S. Ullmann, A. M. Molenbroek P. M. Sarro, H. W. Zandbergen, Ultramicroscopy 2008, 108, 993-998.

[36] S. A. Song, W. Zhang, H. S. Jeong, J. G. Kim, Y. J. Kim, Ultramicroscopy 2008, 108, 1408-1419.

[37] K. N. Kushita, K. Hojou, S. Furuno, Microsc. Microanal. Microstruct. 1995 6, 149-157.

[38] A. P. Hitchcock, J. J. Dynes, G. Johansson, J. Wang, G. Botton, Micron 2008, 39, $741-748$.

[39] R. Fink, M. R. Weiss, E. Umbach, D. Preikszas, H. Rose, R. Spehr, P. Hartel, W. Engel, R. Degenhardt, R. Wichtendahl, H. Kuhlenbeck, W. Erlebach, K. Ihmann, R. Schlogl, H. J. Freund, A. M. Bradshaw, G. Lilienkamp, T. Schmidt, E. Bauer, G. Benner, J. Electron Spectrosc. Relat. Phenom. 1997, $84,231-250$.

[40] S. Anders, H. A. Padmore, R. M. Duarte, T. Renner, T. Stammler, A. Scholl, M. R. Scheinfein, J. Stohr, L. Seve, B. Sinkovic, Rev. Sci. Instrum. 1999, 70, 3973-3981.

[41] E. Bauer, Rep. Prog. Phys. 1994, 57, 895-938.

[42] P. E. Batson, N. Dellby, O. L. Krivanek, Nature 2002, 418, 617-620.

[43] D. A. Muller, Nat. Mater. 2009, 8, 263-270.

[44] D. A. Muller, L. F. Kourkoutis, M. Murfitt, J. H. Song, H. Y. Hwang, J. Silcox, N. Dellby, O. L. Krivanek, Science 2008, 319, 1073-1076.

[45] M. P. Seah, W. A. Dench, Quantitative Electron Spectroscopy of Surfaces: A Standard Data Base for Electron Inelastic Mean Free Paths in Solids, Surface and Interface Anal. 1, 2, 1979.

[46] W. Chao, J. Kim, S. Rekawa, P. Fischer, E. H. Anderson, Opt. Express 2009, $17,17669-17677$.

[47] Y. T. Chen, T. N. Lo, Y. S. Chu, J. Yi, C. J. Liu, J. Y. Wang, C. L. Wang, C. W. Chiu, T. E. Hua, Y. Hwu, Q. Shen, G. C. Yin, K. S. Liang, H. M. Lin, J. H. Je, G. Margaritondo, Nanotechnology 2008, 19, 5. 
[48] J. D. Grunwaldt, B. Kimmerle, A. Baiker, P. Boye, C. G. Schroer, P. Glatzel, C. N. Borca, F. Beckmann, Catal. Today 2009, 145, 267-278.

[49] A. M. Beale, S. D. M. Jacques, J. A. Bergwerff, P. Barnes, B. M. Weckhuysen, Angew. Chem. 2007, 119, 8988-8991; Angew. Chem. Int. Ed. 2007 46, 8832-8835.

[50] L. Espinosa-Alonso, M. G. O'Brien, S. B. M. Jacques, A. M. Beale, K. P. de Jong, P. Barnes, B. M. Weckhuysen, J. Am. Chem. Soc. 2009, 131 $16932-16938$

[51] M. Havecker, A. Knop-Gericke, T. Schedel-Niedrig, R. Schlogl, Angew. Chem. 1998, 110, 2049-2053; Angew. Chem. Int. Ed. 1998, 37, 1939 1942.

[52] W. M. Heijboer, A. A. Battiston, A. Knop-Gericke, M. Havecker, H. Bluhm, B. M. Weckhuysen, D. C. Koningsberger, F. M. F. de Groot, Phys. Chem. Chem. Phys. 2003, 5, 4484.

[53] E. de Smit, F. M. F. de Groot, R. Blume, M. Havecker, A. Knop-Gericke, B. M. Weckhuysen, Phys. Chem. Chem. Phys. 2010, 12, 667.

[54] D. A. Fischer, K. Efimenko, R. R. Bhat, S. Sambasivan, J. Genzer, Macromol. Rapid Commun. 2004, 25, $141-149$.

[55] S. Sambasivan, D. A. Fischer, B. M. DeKoven, A. Kuperman, Adv. Mater. 2000, 12, 1809-1813.

[56] I. J. Drake, T. C. N. Liu, M. Gilles, T. Tyliszczak, A. L. D. Kilcoyne, D. K. Shuh, R. A. Mathies, A. T. Bell, Rev. Sci. Instrum. 2004, 75, 3242-3247.

[57] I. Swart, E. de Smit, B. M. Weckhuysen, F. M. F. de Groot, unpublished results, 2007.

[58] E. de Smit, I. Swart, J. F. Creemer, G. H. Hoveling, M. K. Gilles, T. Tyliszczak, P. J. Kooyman, H. W. Zandbergen, C. Morin, B. M. Weckhuysen, F. M. F. de Groot, Nature 2008, 456, 222-239.
[59] E. de Smit, I. Swart, J. F. Creemer, C. Karunakaran, D. Bertwistle, H. W. Zandbergen, F. M. F. de Groot, B. M. Weckhuysen, Angew. Chem. 2009, 121, 3686-3690; Angew. Chem. Int. Ed. 2009, 48, 3632- 3636.

[60] B. Bozzini, L. D'Urzo, A. Gianoncelli, B. Kaulich, M. Prasciolu, I. Sgura, E. Tondo, M. Kiskinova, J. Phys. Chem. C 2009, 113, 9783-9787.

[61] J. M. Thomas, J. C. Hernandez-Garrido, Angew. Chem. 2009, 121, 3962 3965; Angew. Chem. Int. Ed. 2009, 48, 3904-3907.

[62] R. F. Egerton, P. Li, M. Malac, Micron 2004, 35, 399-409.

[63] M. Bosman, V. J. Keast, J. L. Garcia-Munoz, A. J. D'Alfonso, S. D. Findlay, L. J. Allen, Phys. Rev. Lett. 2007, 99.

[64] F. Carbone, O. H. Kwon, A. H. Zewail, Science 2009, 325, 181 - 184

[65] P. Fischer, IEEE Trans. Magn. 2008, 44, 1900-1904.

[66] E. G. Rightor, A. P. Hitchcock, H. Ade, R. D. Leapman, S. G. Urquhart, A. P. Smith, G. Mitchell, D. Fischer, H. J. Shin, T. Warwick, J. Phys. Chem. B 1997, 101, 1950-1960.

[67] A. Braun, A. Kubatova, S. Wirick, S. B. Mun, J. Electron Spectrosc. Relat Phenom. 2009, 170, $42-48$.

[68] M. R. Howells, T. Beetz, H. N. Chapman, C. Cui, J. M. Holton, C. J. Jacobsen, J. Kirz, E. Lima, S. Marchesini, H. Miao, D. Sayre, D. A. Shapiro, J. C. H. Spence, D. Starodub, J. Electron Spectrosc. Relat. Phenom. 2009, 170, 4-12.

[69] J. Wang, C. Morin, L. Li, A. P. Hitchcock, A. Scholl, A. Doran, J. Electron Spectrosc. Relat. Phenom. 2009, 170, 25-36.

[70] M. R. Howells, A. P. Hitchcock, C. J. Jacobsen, J. Electron Spectrosc. Relat Phenom. 2009, 170, 1-3.

Received: December 22, 2009

Published online on March 19, 2010 